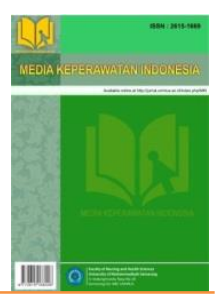

\title{
Family Support On Severe Frequency In Epilepsy Patients In RSUP. Dr. Kariadi Semarang
}

\author{
Theresia Ika ${ }^{1}$, Eni Hidayati ${ }^{2}$
}

1,2 University of Muhammadiyah Semarang

\begin{tabular}{|c|c|c|}
\hline Article Info & & Abstract \\
\hline $\begin{array}{l}\text { Article History: } \\
\text { Accepted February } \\
2019 \\
\text { Key words: } \\
\text { mily support; } \\
\text { epilepsy; } \\
\text { seizure frequency }\end{array}$ & 19th & $\begin{array}{l}\text { Background: This epilepsy is considered a burden for the patient, the } \\
\text { family and is considered an embarrassing disease, infectious disease and } \\
\text { mental illness that makes the epileptic patient difficult to live a normal life, } \\
\text { often experiencing discrimination in terms of learning, work, or in } \\
\text { marriage. Objective: to know family support for the occurrence of seizure } \\
\text { frequency in epilepsy patients. Research Method: Type of qualitative } \\
\text { research using the phenomenological approach. The sampling technique is } \\
\text { done by using purposive sampling approach. Excavation of this data is done } \\
\text { by conducting in-depth interviews with the object or the respondent. } \\
\text { Results: The support provided by the family in the form of explaining and } \\
\text { teaching the treatment of epilepsy, helping and protecting the respondents } \\
\text { in the treatment of epilepsy, support in terms of providing treatment and } \\
\text { financing and providing love and trust. It is expected that families can } \\
\text { provide good support, so that will reduce the incidence of seizure } \\
\text { frequency that appears and can improve the quality of life of respondents. }\end{array}$ \\
\hline
\end{tabular}

\section{PENDAHULUAN}

Epilepsi sudah dikenal masyarakat sejak abad ke 19 (Ginsberg., 2008). Pemahaman masyarakat tentang epilepsi masih kurang, baik dalam hal perawatan penderita epilepsi maupun dalam hal dukungan dari anggota keluarga terhadap penderita epilepsi tersebut. Pemahaman masyarakat yang masih kurang dapat membuat penderita epilepsi tidak dapat terdiagnosa dan tidak mendapatkan pelayanan kesehatan yang baik. Penderita epilepsi yang tidak dapat terdiagnosa dan tidak mendapatkan pelayanan kesehatan yang baik dapat menyebabkan kematian atau resiko adanya gangguan pada sistem saraf pusat (Harsono, Epilepsi (buku kedua), 2017).

Berdasarkan data dari organisasi kesehatan dunia (WHO, 2017) sekitar 50 juta orang saat ini hidup dengan epilepsi di seluruh dunia. Perkiraan proporsi populasi umum dengan epilepsi aktif (yaitu kejang terusmenerus atau dengan kebutuhan pengobatan) pada waktu tertentu adalah antara 4 dan 10 per 1000 orang. Namun, beberapa studi di negara berpenghasilan rendah dan menengah menunjukkan bahwa proporsinya jauh lebih tinggi, antara 7 dan 14 per 1000 orang. Di Indonesia, angka kejadian epilepsi adalah 6 dari 1000 orang atau sekitar 2 juta orang menderita epilepsi. Wilayah Jawa Tengah, angka kejadian

\footnotetext{
Corresponding author:

Theresia Ika

therikaseptiana@gmail.com

Media Keperawatan Indonesia, Vol 2 No 1, February 2019

e-ISSN: 2615-1669

DOI:10.26714/mki.2.1.2019.21-28
} 
epilepsi adalah sekitar 214.000 orang menderita epilepsi. Berdasarkan data sejak bulan Juli 1999 - Desember 2009 ada sejumlah 500 orang yang menderita epilepsi, baik yang rawat jalan maupun yang dirawat di Rumah Sakit Umum Pusat Dr. Kariadi Semarang (Mardlani, 2010).

Dalam banyak hal, epilepsi ini dianggap sebagai beban bagi penderita dan keluarga karena bagi orang awam hal ini dianggap sebagai penyakit yang memalukan, penyakit menular dan penyakit jiwa. Anggapan masyarakat yang demikian membuat penderita epilepsi sulit hidup dalam kehidupan yang normal. Penderita epilepsi sering mengalami diskriminasi, baik dalam hal mendapatkan pelajaran, pekerjaan, maupun dalam hal berumah tangga. Bahkan masih banyak anggapan bahwa, penyakit epilepsi dapat diturunkan juga dari orang tua ke anak. Hal ini membuat beban bagi penderita yang ingin menikah dan memiliki keturunan (Hawari, 2010).

Dukungan keluarga baik dari segi financial, emosional maupun dari segi spiritual sangat dibutuhkan bagi pasien yang menjalani pengobatan dalam jangka waktu yang panjang dan pasien kanker. Dengan meningkatnya dukungan keluarga ini maka pasien ini akan mempunyai motivasi untuk sembuh. Dengan adanya motivasi untuk sembuh ini maka individu tersebut akan mengikuti prosedur pengobatannya dengan baik dan lancar (Saragih, 2010). Dukungan keluarga yang baik akan meningkatkan kemampuan psikososial pasien (Yanto \& Setyawati, 2017).

Demikian juga yang terjadi pada pasien epilepsi, faktor pendukung dari keberhasilan pengobatan epilepsi ini adalah adanya dukungan dari keluarga. Dukungan dari keluarga diperlukan untuk mengingatkan pasien supaya rutin dan disiplin dalam mengkonsumsi obat anti epilepsi. Dengan rutin meminum obat epilepsi ini akan mengurangi frekuensi kejang pada pasien epilepsi. Apabila tidak ada dukungan dari keluarga, maka dapat mengakibatkan frekuensi kejang muncul lebih sering dari biasanya. Dengan munculnya frekuensi kejang yang lebih sering ini maka akan terjadi perubahan atau peningkatan dosis dan kombinasi obat obat anti epilepsi, yang sebenarnya hal ini tidak perlu terjadi apabila pasien patuh atau disiplin dalam mengkonsumsi obat anti epilepsi (Harsono, Epilepsi, 2001).

Berdasarkan latar belakang permasalahan di atas, maka diperlukan penelitian lebih lanjut tentang adanya dukungan keluarga pada kejadian frekuensi kejang pada pasien epilepsi. Diharapkan dengan adanya dukungan keluarga yang optimal dalam merawat pasien epilepsi dan rutin mengkonsumsi obat - obat anti epilepsi secara rutin dapat membuat frekuensi kejang menjadi berkurang atau bahkan tidak pernah muncul lagi.

\section{METODOLOGI PENELITIAN}

Desain penelitian ini menggunakan jenis penelitian kualitatif dengan menggunakan pendekatan fenomenologis. Tehnik pengambilan sampel ini dilakukan dengan menggunakan pendekatan purposive Sampling. Penggalian data ini dilakukan dengan melakukan wawancara secara mendalam kepada objek atau responden. Jumlah sampel dalam penelitian ini tidak terbatas, bila sudah mencapai saturasi ) maka pengambilan data dari subjek yang berikutnya akan dihentikan.

Etika penelitian meliputi Informent consen, Anonimity, Beneficiency, Justice, dan Confidentiality.

\section{HASIL PENELITIAN}

Hasil penelitian menunjukkan bahwa dukungan keluarga yang teridentifikasi beberapa tema antara lain: dukungan informasional, dukungan penilaian, dukungan instrumental dan dukungan emosional. 
1. Dukungan Informasional

Berdasarkan dari hasil penelitian, pada umumnya keluarga dapat menjelaskan hal - hal yang dapat menyebabkan kejang dan keluarga dapat mengajarkan koping yang tepat pada saat terjadinya kejang. Sub tema yang teridentifikasi antara lain kemampuan menjelaskan dan mengajarkan.

\section{Dukungan Penilaian}

Berdasarkan dari hasil wawancara di atas, pada umumnya partisipan dapat mengungkapkan apa saja tindakan yang dilakukan keluarga untuk membimbing atau mencegah masalah kejang terjadi kembali kepada partisipan. Sub tema yang teridentifikasi antara lain: membantu dan melindungi.

\section{Dukungan Instrumental}

Berdasarkan hasil wawancara diatas, pada umumnya partisipan dapat menyampaikan dan menyebutkan wujud/ tindakan nyata yang dilakukan oleh keluarga dalam rangka menolong penderita epilepsi secara langsung. Sub tema yang teridentifikasi antara lain: keluarga melakukan Pengobatan dan pembiayaan.

\section{Dukungan Emosional}

Berdasarkan hasil wawancara di atas, partisipan dapat mengungkapkan bahwa keluarga memberikan perhatian, cinta dan simpati kepada partisipan sehingga partisipan merasa diperhatikan dan dicintai oleh keluarga secara utuh. Sub tema yang teridentifikasi antara lain: memberi kasih sayang dan kepercayaan.

\section{PEMBAHASAN}

\section{Dukungan Informasional}

Berdasarkan dari hasil penelitian, pada umumnya keluarga dapat menjelaskan hal hal yang dapat menyebabkan kejang dan keluarga dapat mengajarkan koping yang tepat pada saat terjadinya kejang. a. Menjelaskan

Proses komunikasi tidak hanya sebatas proses menyampaikan pesan dari komunikator kepada komunikan, tetapi berawal dari proses berfikir dan produksi pesan dari dalam diri komunikator. Berfikir dan memproduksi pesan dipengaruhi oleh bagaimana kondisi psikologis dalam diri komunikator (Sri Dewi, 2015). Dukungan ini dapat meningkatkan kepercayaan dan rasa aman partisipan. Dukungan yang diberikan dalam bentuk informasi selama perawatan berlangsung akan berdampak positif (Febria, 2018).

Berdasarkan dari hasil penelitian, partisipan mengungkapkan bahwa keluarga dapat menjelaskan tentang hal - hal yang dapat menyebabkan kejang. Dengan adanya penjelasan hal - hal yang dapat menyebabkan kejang tersebut akan membuat partisipan mengurangi hal - hal tersebut yang akan berdampak terjadinya penurunan frekuensi kejang pada partisipan.

Menurut Supratiknya (1995, h.85) penerimaan diri berkaitan dengan kerelaan membuka diri atau mengungkapkan pikiran, perasaan dan reaksi kepada orang lain, kesehatan psikologis individu serta penerimaan terhadap orang lain. Penerimaan diri diawali dengan keikhlasan dan kepasrahan subjek untuk menerima kenyataan bahwa mereka menderita epilepsi kemudian akan berkembang pada penerimaan dirinya secara utuh. Mengenali kelemahan serta mengembangkan potensi dan kelebihan dirinya agar subjek bisa menjalankan kehidupannya secara optimal (Eki vina, 2008).

Secara umum dapat didapatkan hasil bahwa peran keluarga dalam menjelaskan hal - hal yang dapat menyebabkan kejang akan menumbuhkan dampak yang positif 
kepada partisipan sehingga akan muncul penerimaan diri secara utuh. Munculnya penerimaan diri secara utuh akan membantu partisipan di dalam proses penyembuhan.

b. Mengajarkan

Menurut Gottieb (1983) dalam Nursalam \& Kurniawati (2007) Dukungan keluarga adalah dukungan yang diberikan oleh keluarga yang terdiri atas informasi atau nasihat verbal dan non verbal, bantuan nyata atau tindakan nyata akan mempunyai manfaat emosional atau efek perilaku bagi pihak penerima. Dukungan keluarga dapat membantu menumbuhkan motivasi melakukan pengobatan (Wahyudi, 2015).

Agar proses kesembuhan partisipan dapat segera terwujud maka dibutuhkan adanya kerjasama yang terjalin dengan baik antara partisipan dan keluarganya ( Siti N, 2011). Menurut penelitian Megawati (2011) kehadiran keluarga yang sangat memperhatikan dan peduli terhadap partisipan menunjukkan dukungan keluarga yang tinggi dalam bentuk memberikan informasi dapat mengurangi beban partisipan dalam menjalani pengobatan.

Secara keseluruhan dapat disimpulkan bahwa kehadiran keluarga dalam memberikan informasi atau nasehat secara verbal maupun non verbal akan menimbulkan manfaat emosional dan efek yang positif bagi partisipan sehingga membantu menumbuhkan motivasi untuk melakukan pengobatan.

\section{Dukungan Penilaian}

Berdasarkan dari hasil wawancara di atas, pada umumnya partisipan dapat mengungkapkan apa saja tindakan yang dilakukan keluarga untuk membimbing atau mencegah masalah kejang terjadi kembali kepada partisipan. a. Membantu

Optimisme pada ODE dapat membantu ODE untuk menyikapi kejadian yang dialaminya secara positif. Hal ini senada dengan hasil penelitian Kung, Rummans, Colligan, dan Clark (2006) pada para penderita kanker, yang menunjukkan bahwa optimisme berhubungan dengan tingginya kualitas hidup. Adanya rasa optimis dapat membantu ODE dalam menyikapi gangguan epilepsi yang dimilikinya (Mrabet, Zouari, dan Ghachem, 2004). Optimisme membantu ODE dalam melakukan pertolongan sendiri ketika sedang meng-hadapi permasalahan, dan juga menjadi motif tersendiri bagi ODE untuk terus berusaha mencapai kualitas hidup yang lebih baik.

Menurut Pitaloka mengemukakan bahwa kesuksesan seseorang dalam pencapaian tujuan ditentukan oleh kemampuannya dalam mengatasi rintangan, pemicu stres, kemampuannya menghasilkan emosi positif, dan usahanya dalam mencapai tujuan.

Secara keseluruhan dapat disimpulkan bahwa dengan adanya optimisme yang positif dari keluarga maupun dari partisipan dapat membantu dalam menyikapi masalah epilepsi yang dimiliki sehingga dapat memotivasi untuk mencapai kualitas hidup yang lebih baik. Dengan tercapainya kualitas hidup yang lebih baik maka akan mengurangi juga frekuensi kejang tersebut muncul.

b. Melindungi

Reaksi lain yang muncul adalah rasa cemas berlebihan terhadap bahaya yang akan dihadapi penderita pada saat munculnya bangkitan, dan akhirnya akan menjelma menjadi sikap terlalu melindungi (parental overprotective). Penderita akan memiliki sifat penakut, seialu merasa tidak aman (illsecure), manja, tidak dewasa dan mempunyai 
tingkat ketergantungan (dependency) yang tinggi. Sifat-sifat tersebut muncul karena hilangnya kesempatan melakukan berbagai aktivitas sebagaimana individu normal lainnya (Laidlaw \& Richens, 1976).

Menurut Alib (2016) epilepsi juga berpotensi mengakibatkan cidera fisik, kelemahan pada fisik dan penurunan kesadaran. Maka dari itu diperlukan penanganan dan edukasi yang lama terhadap penderita dan keluarga, jika tidak segera diatasi epilepsi akan berdampak buruk terhadap perkembangan perilaku dan juga akan berdampak pada kesehatan (cidera fisik). Untuk meminimalkan cidera fisik maka dibutuhkan pendidikan kesehatan pada keluarga tentang penanganan dan penatalaksanaan saat kejang, tujuannya adalah untuk mendeskripsikan mengantisipasi, mencegah dan meminimalkan cidera fisik.

Secara keseluruhan diungkapkan bahwa dengan adanya dukungan dari keluarga dalam melakukan penanganan pada saat kejang itu muncul maka akan meminimalkan dan melindungi partisipan terhadap terjadinya cidera fisik pada saat partisipan mengalami kejang.

\section{Dukungan Instrumental}

Berdasarkan hasil wawancara diatas, pada umumnya partisipan dapat menyampaikan dan menyebutkan wujud/ tindakan nyata yang dilakukan oleh keluarga dalam rangka menolong penderita epilepsi secara langsung.

a. Melakukan Pengobatan

Berdasarkan pernyataan dari beberapa responden, ternyata ada satu responden yang kurang mendapatkan dukungan dari salah satu keluarga, yaitu ayah. Karena selama masa perawatan responden tidak pernah ditunggu oleh ayahnya. Yang mendampingi responden saat masa perawatan adalah ibu. Perhatian lebih banyak diberikan oleh ibu responden.

Menurut Fajar (2012) frekuensi kejang yang tinggi, waktu kejang yang panjang, dan episode status epileptikus memiliki kecenderungan untuk menyebabkan penurunan fungsi kongnitif. Pengobatan yang tidak adekuat terhadap epilepsi yang terjadi dalam jangka waktu lama menyebabkan terganggunya fungsi psikososial yang berdampak pada menurunnya kualitas hidup (pencapaian akademik yang rendah, tidak mandiri dan gaya hidup yang terbatas). Berdasarkan penelitian Hayati (2016) terapi utama epilepsi berupa obat-obat antiepilepsi (OAE) di berikan agar kejang dapat di kontrol. Untuk mengurangi bangkitan kejang maka di perlukan kepatuhan pasien dalam berobat. Kegagalan dalam meminum obat secara teratur dapat berakibat terjadinya resistensi obat, reaksi obat, peningkatan morbiditas dan mortalitas serta mengurangi kualitas hidup.

Dengan adanya dukungan keluarga dalam melakukan pengobatan maka dapat mengurangi frekuensi bangkitan kejang muncul selain itu dapat mencegah terjadinya resistensi obat, reaksi obat dan dapat meningkatkan kualitas hidup partisipan.

b. Pembiayaan

Menurut Sumidjo ( 2006) bahwa social ekonomi merupakan faktor yang sangat berpengaruh terhadap tingkah laku seseorang. Keadaan ekonomi keluarga mampu mencukupi dan menyediakan fasilitas serta kebutuhan untuk keluarga. Sehingga semakin tinggi sosial ekonomi keluarga maka motivasi pasien untuk sembuh pun berbeda beda. 
Menurut penelitian wahyudi (2011) Apabila dikaitkan dengan motivasi sembuh, pekerjaan yang dilihat dari social ekonomi keluarga maka dengan status ekonomi yang dimiliki keluarga akan mempunyai dukungan dan motivasi untuk sembuh lebih tinggi daripada status ekonomi yang lebih rendah.

Dengan adanya dukungan keluarga dalam social ekonomi ini dapat disimpulkan bahwa dukungan keluarga dapat meningkatkan motivasi pada diri partisipan untuk berusaha sembuh, sehingga dengan adanya motivasi tersebut maka diharapkan akan mengurangi kemunculan frekuansi kejadian kejang pada diri partisipan.

\section{Dukungan Emosional}

Berdasarkan hasil wawancara di atas, partisipan dapat mengungkapkan bahwa keluarga memberikan perhatian, cinta dan simpati kepada partisipan sehingga partisipan merasa diperhatikan dan dicintai oleh keluarga secara utuh.

a. Memberi kasih sayang

Menurut penyataan Mery ( 2008) bahwa dukungan dari orang terdekat atau keluarga akan mengurangi rasa tidak nyaman yang dirasakan oleh partisipan. Keluarga berperan penting dalam keberhasilan dari pengobatan karena dukungan keluarga akan mempengaruhi tingkah laku dan tingkah laku ini memberikan hasil kesehatan sesuai yang diinginkan. Yang terpenting adalah memberikan support dan perhatian yang lebih pada pasien epilepsi.

Menurut pendapat Sarafino ( 1998) dalam Sujono (2008) bahwa dukungan keluarga dapat bermanfaat positif bagi kesehatan pasien apabila pasien merasakan dukungan tersebut sebagai dukungan yang layak dan sesuai dengan apa yang pasien butuhkan. Selain itu, pengaruh positif dari dukungan keluarga adalah pada penyesuaian dalam mengahadapi masalah atau stress.

Hal ini dapat disimpulkan bahwa dengan adanya support dan perhatian lebih kepada pasien epilepsi maka akan memberikan dampak yang positif sehingga akan mengurangi perasaan yang tidak nyaman yang dirasakan oleh partisipan. Dengan adanya dukungan ini maka memberikan peranan penting dalam keberhasilan pengobatan. Apabila pengobatan berhasil maka akan meningkatkan kualitas hidup pasien sehingga frekuensi kejang tidak akan muncul kembali.

b. Kepercayaan

Model keyakinan kesehatan seseorang akan mempengaruhi upaya mencari pengobatan. Berbagai upaya pendidikan kesehatan, pemberian psiko-edukasi terhadap keluarga yang sedang menunggu salah satu anggota keluarga yang dirawat di rumah sakit (Yusuf, 2013).

Dukungan keluarga yang diberikan dapat menumbuhkan motivasi untuk melakukan pengobatan, dukungan keluarga yang diberikan dapat berbentuk perhatian secara emosi dengan kesediaan keluarga menemani pasien dalam menjalani pengobatan. Dukungan keluarga ini akan menenangkan hati pasien dalam menjalani pengobatan. Hal ini sesuai dengan Sari (2010) yang menyatakan dukungan merupakan faktor yang penting yang dibutuhkan seseorang dalam menghadapi masalah kesehatan.

Dengan adanya kepercayaan atau keyakinan dari pihak keluarga untuk terus memberikan perhatian maupun dukungan secara emosional maka dapat menumbuhkan motivasi atau semangat partisipan untuk terus menjalani pengobatan, sehingga dengan menjalani 
pengobatan secara rutin dapat membantu meningkatkan kualitas hidup partisipan dan akan mengurangi frekuensi kejadian kejang muncul.

Berdasarkan masing - masing dukungan yang telah dijelaskan di atas maka dapat diambil kesimpulan bahwa pada penderita epilepsi dukungan keluarga yang sangat dibutuhkan adalah dukungan emosional. Dukungan emosional ini diberikan dalam bentuk memberi perhatian dan kepercayaan sehingga penderita dapat termotivasi / bersemangat dalam menjalani pengobatan secara rutin dan dapat meningkatkan kualitas hidup penderita yang akan berdampak pada berkurangnya frekuensi kejadian kejang yang muncul.

\section{Simpulan}

Berdasarkan hasil penelitian dan uraian pembahasan di atas dapat disimpulkan bahwa karakteristik dari keluarga pada penderita epilepsi di Rumah Sakit Kariadi Semarang adalah keluarga yang memberikan dukungan penuh kepada responden. Dukungan yang diberikan dalam bentuk peran serta keluarga memberikan penjelasan dan mengajarkan penanganan tentang penyakit epilepsi, membantu dan melindungi responden dalam menangani epilepsi, mendukung dalam hal memberikan pengobatan dan pembiayaan serta memberikan kasih sayang dan kepercayaan penuh kepada responden. Dengan adanya dukungan tersebut maka responden menjadi termotivasi untuk berusaha sembuh dan rutin dalam menjalani pengobatan, sehingga akan mengurangi kejadian frekuensi kejang yang muncul dan dapat meningkatkan kualitas hidup responden.

\section{REFERENSI}

Batitcaca, \& B, F. (2008). Asuhan Keperawatan pada Klien dengan Gangguan Sistem Persarafan jilid I. Jakarta.

Fisher, R. (2014). Practical Clinical Definition of epilepsy. Epilepsia.
Ginsberg. (2008). Lecture Notes Neurologi. In Lecture Notes Neurologi. Jakarta.

Haq, N. Z. (2011). Asuhan Keperawatan Epilepsi. Surabaya: http://nuzululfkp09.web.unair.ac.id.

Harsono. (2001). In Epilepsi. Yogyakarta: Gadjah Mada University Press.

Harsono. (2017). Epilepsi (buku kedua). In Epilepsi (buku kedua) (p. 241). Yogyakarta: UGM PRESS.

Harsono. (2008). The Quality of Life of Epileptic Patient. Jakarta: Universa Medicina Fakultas Kedokteran Universitas Trisakti.

Harsono, P. D. (2001). Hand Out Epilepsi. Surabaya.

Hawari, I. (2010). Epilepsi di Indonesia. Jakarta: Official Website of Yayasan Epilepsi Indonesia dan Club Epsi.

Hertisa, D. (2013). Morbiditas Epilepsi di Poliklinik Saraf RS PKU Muhammadiyah Yogyakarta Periode Juli 2010 - Juli 2011, 89.

Hidayat, A. (2007). Riset Keperawatan dan Tehnik Penulisan Ilmiah . Jakarta: Salemba Medika.

Mardlani, D. (2010, April 19). Retrieved Juli 2017, from http://infobedah.blogspot.co.id/2010/08/penderitaepilepsi-tersebar-di-seluruh.html.

NUGROHO, A. A. (2016). UPAYA PENCEGAHAN CIDERA FISIK PADA ANAK DENGAN EPILEPSY DI RSUD PANDAN ARANG BOYOLALI. Surakarta: -.

PERDOSSI. (2017). In Pedoman Penatalaksanaan Epilepsi (pp. 3 - 13). Surabaya: Airlangga University Press.

Pinzon, R. (2007). Dampak Epilepsi pada Aspek Kehidupan Penyandangnya. In C. D. 157. Jakarta: Group PT Kalbe Farma.

Pramujiwati, D. (2013). PEMBERDAYAAN KELUARGA DAN KADER KESEHATAN JIWA DALAM. Bogor Utara: Jurnal Keperawatan Jiwa Volume 1 Nomer 2.

Primardi, A. (2010). OPTIMISME, HARAPAN, DUKUNGAN SOSIAL KELUARGA, DAN KUALITAS HIDUP ORANG DENGAN EPILEPSI. Semarang: Jurnal Psikologi volume 3 No 2. 
S, A. Y. (2010). TERAPI KELUARGA DENGAN PENDEKATAN SPIRITUAL TERHADAP MODEL. Surabaya: Fakultas Keperawatan Universitas Airlangga.

Saragih, R. (2010). Peranan Dukungan Keluarga dan Koping Pasien dengan Penyakit Kanker Terhadap Pengobatan Kemoterapi di RB 1 Rumah Sakit Umum Pusat Haji Adam Malik Medan Tahun 2010, 1 - 5.

Shafer. (2013). FAQs for Epilepsy Monitoring Unit. UK.

Shorvon, S. (2010). Definitions and epidemiology. UK: Wiley-Blackwell.

Sugiyono. (2015). Metode Penelitian Kuantitatif Kualitatif. Bandung : Alfabeta.
Suyanto, B. \&. (2011). Metode Penelitian Sosial. Jakarta: Kencana.

WHO. (2017, Februari). Retrieved Juni 20, 2017, from Epilepsi: http://www.who.int/mediacentre/factsheets /fs999/en/

Winknjosastro. (1997). Kehamilan dan Janin dengan Risiko Tinggi dalam Ilmu Kebidanan. Jakarta: Yayasan Bina Pustaka.

Yanto, A., \& Setyawati, D. (2017). Dukungan Keluarga Pada Pasien Diabetes Mellitus Tipe 2 Di Kota Semarang. In Seminar Nasional Universitas Muhammadiyah Semarang (Vol. 1). Universitas Muhammadiyah Semarang: LPPM Universitas Muhammadiyah Semarang. Retrieved from http://eriset.unimus.ac.id/index.php/psn120 12010/index 